\title{
Effects of Oral Supplementation of Vitamin E on Fragility of RBC in Hemolytic Anemic Patients with G6PD Deficiency
}

\author{
Nayma Sultana ${ }^{1}$, Noorzahan Begum², Shelina Begum ${ }^{3}$, Sultana Ferdousi ${ }^{4}$, Taskina $\mathrm{Ali}^{4}$ \\ ${ }^{1}$ Assistant Professor, Department of Physiology, Sir Salimullah Medical College, Dhaka, ${ }^{2}$ Professor and Chairman, Department of Physiology, \\ Bangabandhu Sheikh Mujib Medical University, Dhaka, ${ }^{3}$ Professor, Department of Physiology, Bangabandhu Sheikh Mujib Medical University, \\ Dhaka, ${ }^{4}$ Assistant Professor, Department of Physiology, Bangabandhu Sheikh Mujib Medical University, Dhaka.
}

\begin{abstract}
:
Background: Vitamin E has role in maintaining the integrity of red cell membrane by preventing oxidation of polyunsaturated fatty acids and thereby protects cells from oxidative stress- induced lysis in G6PD deficiency, which can be reflected by changes in osmotic fragility of RBC and some absolute values like MCV, MCH \& MCHC. Objective: To observe the effects of vitamin E supplementation on fragility of RBC in order to evaluate role of this antioxidant vitamin in reducing chronic hemolysis in G6PD deficient patients. Methods: For this, a total number of 102 subjects with age ranged from 5 to 40 years of both sexes were included in the study. Among them 68 were G6PD enzyme deficient patients, of whom 34 were in supplemented group (study group) and 34 were in non-supplemented group (control group). The supplemented group received vitamin $\mathrm{E}$ supplementation for 60 consecutive days at a dose of $800 \mathrm{IU} /$ day for adult and $400 \mathrm{IU} /$ day for children $\leq 12$ years (in a divided dose i,e. 4 times daily). Age and sex matched 34 apparently healthy subjects with normal blood G6PD level were taken to observe the base line data (healthy control) and also for comparison. All the G6PD deficient patients were selected from Out Patient Department (OPD) of Hematology, Bangabandhu Sheikh Mujib Medical University (BSMMU), Dhaka, Bangladesh during the period of July 2005 to June 2006 and all the healthy subjects were selected from personal contact. Blood G6PD level, osmotic fragility of RBC were measured by standard techniques and MCV, MCH, and MCHC were obtained by calculation. All the parameters were measured on day 1 (one) of their first visit and also were on day 60 in deficient group. Data were compared among the deficient groups, also in supplemented group just before and after supplementation. Analysis of data was done by appropriate statistical method. Results: Mean starting and completing points of osmotic fragility of RBC were significantly higher but MCV, MCH, MCHC were significantly lower in patients suffering from hemolytic anemia due to G6PD deficiency in comparison to those of the healthy control. After supplementation with vitamin $\mathrm{E}$ starting and completing points of osmotic fragility of RBC were significantly decreased whereas, MCV, MCH, MCHC were significantly increased towards those of healthy control in supplemented group of patients in comparison to those of their pre-supplemented (day-1) and non-supplemented groups both on day 1 and day 60. Conclusion: From this study it may be concluded that, disturbances of some of the hematological parameter like higher osmotic fragility of RBC and lower MCV, MCH, MCHC occur in G6PD deficient hemolytic anemic patients, which returned towards normal after supplementation of vitamin $\mathrm{E}$, which clearly indicates the role of this anti-oxidant vitamin in maintaining red cell membrane integrity and thereby decreases the rate of hemolysis in this group of patients. So, vitamin E can be supplemented along with other drugs for better management of the patients.
\end{abstract}

Key words: Osmotic fragility, G6PD, hemolytic anemia, vitamin E.

[BSMMU J 2008; 1(1): 6-10]

\section{Introduction:}

Glucose 6-posphate dehydrogenase (G6PD) deficiency is the most common clinically significant enzyme defect in human biology and the common clinical manifestation of this enzyme defect is hemolytic anemia ${ }^{1}$. Acute hemolytic crisis may occur in G6PD deficiency due to some oxidative stress, such as intake of some anti-malarial drugs, ingestion of fava beans, various types of bacterial and viral infection ${ }^{2-4}$.

Address for Correspondence: Dr. Nayma Sultana, Assistant Professor, Department of Physiology, Sir Salimullah Medical College, Dhaka, Bangladesh, E-mail:nayma_sultana@yahoo.com
Hemolysis of RBC may also occur even without prior administration of drugs in G6PD deficiency ${ }^{5-7}$.

Vitamin $\mathrm{E}$ is one of the major lipid soluble antioxidant. It prevents oxidation of polyunsaturated fatty acids and thus protects red blood cells from oxidative stress-induced lyses $^{8}$. Again, deficiency of vitamin $\mathrm{E}$ is a common feature in genetic anemia, including G6PD deficiency hemolytic anemia due to its increased consumption ${ }^{8,9}$. Supplementation of vitamin E may have an important role in maintaining red cell membrane integrity by reducing osmotic fragility of erythrocyte ${ }^{10,11}$ and can minimize the 
severity of hemolysis in G6PD deficient patients ${ }^{12}$. Again, vitamin $\mathrm{E}$ supplementation can restore the required amount of vitamin E level in this group of patients, and thus may prevent hemolysis by improving red blood cells survival 5,6,13. Normal red blood cell indices like MCV, MCH and MCHC may also be found in peripheral blood film by oral supplementation of vitamin $\mathrm{E}^{11}$.

An increase in osmotic fragility of RBC may occur in hemolytic anemia with G6PD deficiency ${ }^{14}$. Mean corpuscular volume (MCV), mean corpuscular hemoglobin $(\mathrm{MCH})$ and mean corpuscular hemoglobin concentration (MCHC) may also decrease in this group of hemolytic anemic patients ${ }^{15,16}$.

However the common clinical consequences of this enzyme deficiency are neonatal jaundice and sporadic hemolytic crisis ${ }^{2}$, can be minimized by vitamin $\mathrm{E}$ supplementation. In our country many people are suffering from hemolytic anemia due to G6PD deficiency. Unfortunately, most of them are treated without knowing the actual cause. Study of the changes in osmotic fragility of RBC and MCV, MCH, MCHC is important as it may reflect the hemolytic crisis in G6PD deficient patients. Evaluation of supplementation of vitamin is equally important in these cases ${ }^{10,11}$.

In Bangladesh there is lack of adequate information about deficiency of G6PD enzyme among the anemic patients. Only one study regarding the hematological parameters of G6PD enzyme deficient patients has been reported in our country ${ }^{17}$. But no published data regarding effects of vitamin E supplementation in these G6PD enzyme deficient patients are available. For this, the present study was aimed at to observe some aspects of hematological parameters in G6PD deficient hemolytic anemic patients both before and after supplementation of vitamin E, in order to explore its role in preventing red cell lyses and thereby maintains the normal hematological status in these enzyme deficient patients. The output of the study may be helpful to create awareness about the deficiency of G6PD enzyme in anemic patients as well as the role of vitamin $\mathrm{E}$ in minimizing the risk of complications. Moreover it can provide information to clinicians for better management of these patients.

\section{Methods:}

The present prospective interventional study was carried out in the Department of Physiology, BSMMU, Dhaka from July 2005 to June 2006. In this study, a total number of 102 subjects with age ranged from 5 to 40 years of both sexes were included. Among them 68 were patients of hemolytic anemia with blood G6PD level below the normal reference range ${ }^{18}$, of whom 34 were in supplemented group (experimental group) and 34 were without supplementation and was considered as nonsupplemented group (control group). The supplemented group received vitamin $\mathrm{E}$ supplementation for 60 consecutive days at a dose of 800 IU/day for adult and 400 IU/day for children $\leq 12$ years; in a divided dose i,e. 4 times daily ${ }^{6,19}$. Age and sex matched 34 apparently healthy subjects with normal blood G6PD level were taken to observe the baseline data (healthy control) and also for comparison. All the G6PD deficient patients were selected from Out Patient Department (OPD) of Hematology, Bangabandhu Sheikh Mujib Medical University (BSMMU), Dhaka, and all the healthy subjects were selected from personal contact. Blood G6PD level, osmotic fragility of RBC and red cell indices (MCV, MCH, MCHC) were done in all the subjects on day 1(one) of their $1^{\text {st }}$ visit and in G6PD enzyme deficient groups of subjects also on day-60. Data were compared among healthy control, supplemented, non-supplemented and also within supplemented groups just before and after supplementation. All the subjects belonged to middle and lower middle socio-economic status. Patients with acute hemolytic episode or received blood transfusion in the last two months and $\beta$ thalassemia trait were excluded from the study. The objectives and benefits of the study were explained to all the subjects to ensure their voluntary participation and a written informed consent was taken from each subject prior to the study.

Two (2) $\mathrm{ml}$ of blood was taken in an EDTA test tube for determination of erythrocyte G6PD level and the hematological parameters..

Erythrocyte G6PD enzyme level was determined by spectrophotometric method ${ }^{20}$ and the hematological parameters were estimated by standard laboratory technique ${ }^{21,22}$. All of these tests were done in the Department of Physiology, BSMMU, Dhaka. Data were expressed as Mean \pm SD. Independent-samples(unpaired) ' $t$ ' test and paired-samples ' $t$ ' test were done as the tests of significance wherever applicable. The statistical analysis was done by using SPSS programme version 12. p value $<0.05$ was considered as significant.

\section{Results:}

Mean erythrocyte G6PD levels were significantly $(p<0.001)$ lower in G6PD enzyme deficient group of patients when compared to that of healthy control (tableI). The mean starting and completing points of osmotic fragility of RBC were significantly $(\mathrm{p}<0.001)$ higher in 
both the G6PD deficient groups in comparison to those of healthy control group on day-1. After supplementation of vitamin E (i,e. on day-60) starting and completing points of osmotic fragility of RBC were significantly $(\mathrm{p}<0.001)$ decreased in comparison to those of their presupplemented (day-1) and also of non-supplemented groups both on day-1 and day-60 and returned almost toward the values of healthy control (table-II).

Patients with G6PD deficiency had significantly $(\mathrm{p}<0.001)$ lower MCV, MCH and MCHC compared to those of healthy control. These values were increased significantly $(p<0.001)$ toward the values of healthy control in G6PD deficient group following vitamin E supplementation. (table-III).

Table-I

Mean ( $\pm S D$ ) Erythrocyte G6PD level in different study groups $(n=102)$.

\begin{tabular}{lccc}
\hline Groups & $\mathrm{n}$ & $\mathrm{U} / 10^{12} \mathrm{RBC}$ & $\mathrm{U} / \mathrm{g} \mathrm{Hb}$ \\
\hline $\mathrm{A}$ & 34 & $191 \pm 18.8$ & $6.69 \pm 1.19$ \\
& & $(161-226)$ & $(5.00-9.60)$ \\
$\mathrm{B}_{1}$ & 34 & $105 \pm 9.38$ & $3.29 \pm 0.34$ \\
& & $(90-121)$ & $(2.38-3.90)$ \\
$\mathrm{C}_{1}$ & 34 & $105 \pm 10.09$ & $3.31 \pm 0.33$ \\
& & $(85-122)$ & $(2.60-3.84)$ \\
\hline
\end{tabular}

Statistical analysis:

\begin{tabular}{ccccc}
\hline & Groups & $\mathrm{p}$ & \multicolumn{2}{c}{ value } \\
\hline $\mathrm{A}$ & vs & $\mathrm{B}_{1}$ & $0.000^{* * *}$ & $0.000^{* * *}$ \\
$\mathrm{~A}$ & vs & $\mathrm{C}_{1}$ & $0.000^{* * *}$ & $0.000^{* * *}$ \\
$\mathrm{~B}_{1}$ & vs & $\mathrm{C}_{1}$ & $0.747^{\mathrm{ns}}$ & $0.893^{\text {ns }}$ \\
\hline
\end{tabular}

Group $\mathbf{A}=$ Healthy subjects for baseline and control.

Group B = Hemolytic anemic patients with G6PD deficiency (Control)

- nonsupplemented group.

Group C = Hemolytic anemic patients with G6PD deficiency (study groupl) - supplemented group.

$\mathrm{B}_{1}$ and $\mathrm{C}_{1}=$ On day $1 ; \mathrm{B}_{2}$ and $\mathrm{C}_{2}=$ On day 60 Values in parentheses indicate ranges
Table-II

Mean ( $\pm S D$ ) Osmotic fragility of RBC in different study groups $(n=102)$

\begin{tabular}{lccc}
\hline Groups & $\mathrm{n}$ & $\begin{array}{c}\text { Starting } \\
\text { point (\%) }\end{array}$ & $\begin{array}{c}\text { Completing } \\
\text { point (\%) }\end{array}$ \\
\hline $\mathrm{A}$ & 34 & $0.48 \pm 0.03$ & $0.31 \pm 0.04$ \\
& & $(0.45-0.55)$ & $(0.25-0.35)$ \\
$\mathrm{B}_{1}$ & 34 & $0.6 \pm 0.04$ & $0.42 \pm 0.032$ \\
& & $(0.5-0.65)$ & $(0.35-0.45)$ \\
$\mathrm{B}_{2}$ & 34 & $0.6 \pm 0.04$ & $0.41 \pm 0.03$ \\
& & $(0.5-0.65)$ & $(0.35-0.45)$ \\
$\mathrm{C}_{1}$ & 34 & $0.59 \pm 0.04$ & $0.42 \pm 0.028$ \\
& & $(0.5-0.65)$ & $(0.35-0.45)$ \\
$\mathrm{C}_{2}$ & 34 & $0.5 \pm 0.04$ & $0.32 \pm 0.04$ \\
& & $(0.4-0.55)$ & $(0.25-0.35)$ \\
\hline
\end{tabular}

Statistical analysis:

\begin{tabular}{lclll}
\hline \multicolumn{3}{c}{ Groups } & \multicolumn{2}{c}{ p value } \\
\hline $\mathrm{A}$ & vs & $\mathrm{B}_{1}$ & $0.000^{* * *}$ & $0.000^{* * *}$ \\
$\mathrm{~A}$ & vs & $\mathrm{C}_{1}$ & $0.000^{* * *}$ & $0.000^{* * *}$ \\
$\mathrm{~A}$ & vs & $\mathrm{B}_{2}$ & $0.000^{* * *}$ & $0.000^{* * *}$ \\
$\mathrm{~A}$ & vs & $\mathrm{C}_{2}$ & $0.245^{\mathrm{ns}}$ & $0.295^{\mathrm{ns}}$ \\
$\mathrm{B}_{1}$ & vs & $\mathrm{C}_{1}$ & $0.314^{\mathrm{ns}}$ & $0.546^{\mathrm{ns}}$ \\
$\mathrm{B}_{2}$ & vs & $\mathrm{C}_{2}$ & $0.000^{* * *}$ & $0.000^{* * *}$ \\
$\mathrm{~B}_{1}$ & vs & $\mathrm{B}_{2}$ & $0.374^{\mathrm{ns}}$ & $0.711^{\mathrm{ns}}$ \\
$\mathrm{C}_{1}$ & vs & $\mathrm{C}_{2}$ & $0.000^{* * *}$ & $0.000^{* * *}$ \\
\hline
\end{tabular}

Group A = Healthy subjects for baseline and control.

Group B = Hemolytic anemic patients with G6PD deficiency (Control) - nonsupplemented group.

Group C = Hemolytic anemic patients with G6PD deficiency (study group) - supplemented group. $\mathrm{B}_{1}$ and $\mathrm{C}_{1}=$ On day $1 . \mathrm{B}_{2}$ and $\mathrm{C}_{2}=$ On day 60 .

Values in parentheses indicate ranges. 
Table-III

Mean ( \pm SD) MCV, MCH and MCHC in different study groups $(n=102)$.

\begin{tabular}{lcccc}
\hline Groups & $\mathrm{n}$ & $\mathrm{MCV}(\mathrm{fl})$ & $\mathrm{MCH}(\mathrm{pg})$ & $\mathrm{MCHC}(\mathrm{g} / \mathrm{dl})$ \\
\hline $\mathrm{A}$ & 34 & $91 \pm 6.65$ & $31 \pm 1.53$ & $34 \pm 2.13$ \\
& & $(73-105)$ & $(26-34)$ & $(28.5-40)$ \\
$\mathrm{B}_{1}$ & 34 & $85 \pm 10.78$ & $27 \pm 2.94$ & $32 \pm 2.1$ \\
& & $(65-104)$ & $(22-33)$ & $(26-33)$ \\
$\mathrm{B}_{2}$ & 34 & $85 \pm 9.37$ & $27 \pm 2.72$ & $32 \pm 2.24$ \\
& & $(67-100)$ & $(22-31)$ & $(26-35)$ \\
$\mathrm{C}_{1}$ & 34 & $85 \pm 9.01$ & $28 \pm 2.83$ & $32 \pm 1.87$ \\
& & $(65-101)$ & $(22-34)$ & $(28-33)$ \\
$\mathrm{C}_{2}$ & 34 & $90 \pm 6.64$ & $30 \pm 2.42$ & $33.5 \pm 0.76$ \\
& & $(77-104)$ & $(26-35)$ & $(32.5-36)$ \\
\hline
\end{tabular}

Statistical analysis:

\begin{tabular}{cccccc}
\hline \multicolumn{3}{c}{ Groups } & \multicolumn{3}{c}{$\mathrm{p}$ value } \\
\hline $\mathrm{A}$ & vs & $\mathrm{B}_{1}$ & $0.025^{*}$ & $0.000^{* * *}$ & $0.010^{*}$ \\
$\mathrm{~A}$ & vs & $\mathrm{C}_{1}$ & $0.015^{*}$ & $0.000^{* * *}$ & $0.018^{*}$ \\
$\mathrm{~A}$ & vs & $\mathrm{B}_{2}$ & $0.019^{*}$ & $0.000^{* * *}$ & $0.000^{* * *}$ \\
$\mathrm{~A}$ & vs & $\mathrm{C}_{2}$ & $0.967^{\mathrm{ns}}$ & $0.851^{\mathrm{ns}}$ & $0.773^{\text {ns }}$ \\
$\mathrm{B}_{1}$ & vs & $\mathrm{C}_{1}$ & $0.895^{\mathrm{ns}}$ & $0.773^{\mathrm{ns}}$ & $0.842^{\text {ns }}$ \\
$\mathrm{B}_{2}$ & vs & $\mathrm{C}_{2}$ & $0.012^{*}$ & $0.000^{* * *}$ & $0.000^{* * *}$ \\
$\mathrm{~B}_{1}$ & vs & $\mathrm{B}_{2}$ & $0.615^{\mathrm{ns}}$ & $0.397^{\mathrm{ns}}$ & $0.136^{\text {ns }}$ \\
$\mathrm{C}_{1}$ & vs & $\mathrm{C}_{2}$ & $0.002^{* *}$ & $0.000^{* * *}$ & $0.002^{* *}$ \\
\hline
\end{tabular}

Group A = Healthy subjects for baseline and control.

Group B = Hemolytic anemic patients with G6PD deficiency (Control)

- nonsupplemented group.

Group C = Hemolytic anemic patients with G6PD deficiency (study group)

- supplemented group.

$\mathrm{B}_{1}$ and $\mathrm{C}_{1}=$ On day $1 ; \mathrm{B}_{2}$ and $\mathrm{C}_{2}=$ On day 60

Values in parentheses indicate ranges.

\section{Discussion:}

The present study revealed that patients with G6PD deficiency have significantly higher osmotic fragility of RBC along with significantly lower values of red cell indices like $\mathrm{MCV}, \mathrm{MCH}, \mathrm{MCHC}$ in comparison to those of healthy control. These findings are in consistent with those of some other researchers of different countries ${ }^{14-}$ 16. On the contrary, no remarkable change in osmotic fragility of RBC and red cell indices were reported. ${ }^{15,23}$.
Again, in this study after 60 days supplementation of vitamin E osmotic fragility in G6PD deficient patients was significantly decreased and it was almost close to those of healthy control. Similar observations were also reported ${ }^{24}$. Red cell indices ( $\mathrm{MCV}, \mathrm{MCH}, \mathrm{MCHC}$ ) were significantly increased and moved towards normal value in the present series of patients. This finding is similar to those of some other researchers ${ }^{11,13}$. On the other hand, no remarkable changes in these values were observed in other studies ${ }^{25}$, which might be due to short duration and low dose of vitamin E supplementation in their studies.

In G6PD deficiency oxidation of polyunsaturated fatty acid on the RBC membrane may increase its susceptibility to hemolysis ${ }^{25}$. In addition, abnormal degradation of hemoglobin, disordered cellular metabolism may also be responsible for early destruction of RBC in G6PD deficient patients ${ }^{11}$. Therefore, early destruction of RBC is the consequence of higher osmotic fragility of RBC in oxidative stress ${ }^{26,27}$. In addition, decreased level of MCV, $\mathrm{MCH}, \mathrm{MCHC}$ in hemolytic anemia with G6PD deficiency is a consequence of excessive hemolysis, more marked under oxidative stress 27,28 .

Therefore, increased osmotic fragility of RBC in G6PD deficiency indicates the presence of membrane defect in the present series of patients. Moreover, decreased MCV, $\mathrm{MCH}$ and MCHC might be due to nutritional deficiency resulting from increased nutritional demand imposed by fragile RBC in this type of patients.

Vitamin E acts as an anti-oxidant by scavenging free radicals, thus prevents premature destruction of $\mathrm{RBC}^{19,25}$. Therefore, supplementation of vitamin E restores osmotic fragility of RBC and thus increases RBC survival ${ }^{9,24}$. However, following vitamin E supplementation decreased osmotic fragility of RBC and shifting of MCV, MCH and MCHC towards normal in the patients of present study are suggestive of protective role of vitamin $E$ supplementation in this group of patients.

Therefore, this study concludes that increase in osmotic fragility and decrease in red cell indices may occur in G6PD deficiency and vitamin E supplementation helps to return these values towards normal. Determination of vitamin E level, red cell half-life and long time supplementation of vitamin $\mathrm{E}$ with larger sample size may be helpful to draw any definite conclusion.

\section{Acknowledgement:}

This work was supported by Department of Physiology BSMMU, Dhaka. 


\section{References:}

1. Beutler E. Glucose-6-phosphate dehydrogenase deficiency. Blood 1994; 84: 3613-3636.

2. Galiano S, Gaetani GF, Barabino A. Favism in the African type of glucose-6-phosphate dehydrogenase deficiency (A). B M J 1990; 300: 236-240.

3. Luzzatto L, Mehta A, Meloni T. Hemoglobinuria and haptoglobin in G6PD deficiency. Br J Haematol 1995 ; 91: 511-512.

4. Gostman I, Muszkat M. Glucose-6-phosphate dehydrogenase deficiency is associated with increased initial clinical severity of acute viral hepatitis. J Gastroenterol Hepatol 2001; 16(1): 12391243.

5. Corash L, Spielberg S, Bartsocas C, Boxer L, Steinherz R, Sheetz M, Schlessleman J, Schulman JD. Reduced chronic hemolysis during high-dose vitamin $\mathrm{E}$ administration in Mediterranean-type glucose-6-phosphate dehydrogenase deficiency. N Eng J Med 1980; 303: 416-420.

6. Hafez M, Amar ES, Zedan M, Hammad H, Sorour AH, Desouky SA, Gami, N. Improved erythrocyte survival with combined vitamin $\mathrm{E}$ and selenium therapy in children with glucose-6phosphate dehydrogenase deficiency and mild chronic hemolysis. J Pediatr1986; 108: 558-561.

7. Chen BH, Tsai JL, Tsai LY, Chao MC. Comparison of serum copper, magnesium, zinc and calcium levels between G6PD deficient and normal Chinese adult. Kaohsiung J Med Sci 1999; 15: 646-650.

8. Chan AC, Chow CK, Chiu D. Interaction of antioxidant and their implication in genetic anemia. Proc Soc Exp Biol Med 1999; 222(3): 274-282.

9. Hasanato RMW. Zinc and antioxidant vitamin deficiency in patients with severe sickle cell anemia. Ann Saudi Med 2006; 26 (1): 17-21.

10. Ono K. Effects of large dose vitamin E supplementation on anemia in hemodialysis patients. Nephron 1985; 40(4): 440-445.

11. Jaja SI, Aigbe PE, Gbenebipse S, Temiyp EO. Changes in erythrocytes following supplementation with alpha-tocopherol in children suffering from sickle cell anemia. Niger Postgrad Med J 2005; 12(2): 110-114.

12. Sarikcioglu S B, Oner G, Tercan E. Antioxidant effect of Egb 761 on hydrogen peroxide-induced lipoperoxidation of G6PD deficient erythrocytes. Phytother Res 2004a;18(10): 837-840.

13. Usberti M, Gerardi GM, Micheli A M, Piola T, Bufano G, Gaggia P, Movilli E, Cancarini GC, Miarinis, SD, D’Avolio G, Broccoli R, Manganoni A, Albertini A, Lorenzo DD. Effects of a vitamin E-bonded membrane and of glutathione on anemia and erythropoietin requirements in hemodyalysis patients. J Nephrol 2002; 15: 558-564.
14. Grattagliano I, Russmann S, Palmieri VO, Juni P, Portineasa P, Palasciano G, Lauterburg BH. Low membrane protein sulfhydrils but not G6PD deficiency prediet ribavirin-induced hemolysis in hepatitis C. Hepatol 2004; 39(5): 1248-1255.

15. Meloni T, Forteleoni G, Ogana A, Franca V. Aspirin-induced acute hemolytic anemia in G6PD deficient children with systemic arthritis. Acta Haemat 1989; 81(4): 208-209.

16. Ajlaan SK, al-Naama LM, al-Naama MM. Correlation between normal glucose-6-phosphate dehydrogenase level and hematological parameters. East Mediterr Health J 2000; 6 (2-3): 391-395.

17. Razzak M. Study on some aspects of hematological indices in G6PD enzyme deficient and non-deficient hemolytic anemia. M.Phil. thesis 2003; BSMMU, Dhaka.

18. Milne DB 2001. Trace elements. In: C.A. Burtis and E.R. Ashwood, (eds). Tietz text book of clinical chemistry, $5^{\text {th }}$ edition. Philadelphia: WB Saunders company, 2001 pp: 568-583.

19. Speilberg SP, Boxer LA, Corash LM, Schulman JD. Improved erythrocyte survival with high-dose vitamin $\mathrm{E}$ in chronic hemolyzing G6PD and glutathione synthetase deficiencies. Ann Intern Med 1979; 90: 53-54.

20. Lab Care Diagnostic (India) Pvt.Ltd. Accurate Glucose-6phosphate dehydrogenase. Quant, Mumbai.2005

21. Luzzatto L, Ropper D. Investigation of Hereditary hemolytic anemias: membrane abnormalities. In: S.J.V. Dace, S.M. Lewis, (eds). Practical hematology. Oxford: Heinemann professional publishing Limited, 1994 pp: 215-247.

22. Dacie SJV and Lewis SM. Practical Hematology. London: ELBS. 1994.

23. Mengel AC, Metz E, Yancy SW. Anemia during acute infections. Arch Int Med 1967; 119: 287-290.

24. Kraus A, Roth H P, Kirchgessner M. Supplementation with vitamin $\mathrm{C}$, vitamin $\mathrm{E}$ or beta-carotene influences osmotic fragility and oxidative damage of erythrocytes of zinc-deficient rats. J Nutr 1997;127: 1290-96.

25. Newman JG, Newman TB, Bowie LJ, Mendelson j. An examination of the role of vitamin $\mathrm{E}$ in glucose-6-phosphate dehydrogenase deficiency. Clin Biochem 1979; 12(5): 149-151.

26. Zinkham HW, Lenhard ER. Metabolic abnormalities of erythrocyte from patient with congenital nonspherocytic hemolytic anemia. J Pediatr 1959;80: 319-336.

27. Rubins J, Young EL. Hereditary spherocytosis. JAMA 1977; 237: 797-798.

28. May J, Mayer CG, Grofterlinder L, Ademowo OG, Mockenhaupt FP, Olumese PE, Falusi AG, Luzzalto L, Bienzle U. Red cell glucose-6-phosphate dehydrogenase status and pyruvate kinase activity in a Nigerian population. Trop Med Int Health 2000; 5(2): 119-123. 